\title{
Post-traumatic stress disorder, psychiatric comorbidities and associated factors among refugees in Nakivale camp in southwestern Uganda
}

Achille Mwira Bapolisi ${ }^{1,2^{*}}$ D, Suzan J. Song ${ }^{3}$, Claire Kesande ${ }^{2}$, Godfrey Zari Rukundo ${ }^{2}$ and Scholastic Ashaba ${ }^{2}$

\begin{abstract}
Background: Armed conflict in Africa has led to displacement of over 24.2 million people, more than 1.4 million of whom are living in Uganda. Studies show that refugees living in Ugandan refugee settlements are at increased risk for post-traumatic stress disorder. However data on the prevalence of other mental health problems among refugees including depression, anxiety and substance use disorder among refugees in Uganda is lacking. Our aim was to determine the prevalence of post-traumatic stress disorder, its main psychiatric comorbidities and perceived psychosocial needs among refugees in Nakivale refugee camp.
\end{abstract}

Methods: We conducted a cross-sectional survey of refugee camp residents $(n=387)$ from nine different countries of origin. Psychiatric disorders were assessed using the MINI International Neuropsychiatric Interview (MINI) and perceived needs by the Humanitarian Emerging Settings Perceived Needs Scale (HESPER).

Results: The prevalence of psychiatric disorders was high among refugees as was the level of perceived needs. The most prevalent psychiatric disorders were generalized anxiety disorders (73\%), post-traumatic stress disorder (PTSD) (67\%), major depressive disorder (58\%) and substance use disorders (30\%). There was a higher level of comorbidity between PTSD and substance use disorder $(\mathrm{OR}=5.13)$, major depressive disorder $(\mathrm{OR}=4.04)$ and generalized anxiety disorder $(\mathrm{OR}=3.27)$.

In multivariate analysis, PTSD was positively associated with the perception of stress as a serious problem (OR $=6.52$; $P$-value $=0.003)$, safety and protection for women in the community $(\mathrm{OR}=2.35$; P-value $=0.011)$, care for family $(O R=2.00 ;$ P-value $=0.035)$ and Place to live in $(O R=1.83$; P-value $=0.04)$. After applying the Bonferroni correction, the perception of stress remained significantly associated with PTSD.

Conclusion: Our findings suggest a strong association between PTSD, its main comorbidities and basic needs in Nakivale refugee camps. Mental health support should include psychological interventions as well as social assistance to improve the health of refugees.

Keywords: Refugees, PTSD, Depression, Anxiety, Alcohol abuse, Pyschosocial needs, Uganda

\footnotetext{
* Correspondence: achilami@yahoo.fr

'Department of Psychiatry, Hôpital Provincial Général de Référence de

Bukavu, Université Catholique de Bukavu, Bukavu, DR, Congo

${ }^{2}$ Department of Psychiatry, Mbarara University of Science and Technology,

Mbarara, Uganda

Full list of author information is available at the end of the article
}

(c) The Author(s). 2020 Open Access This article is distributed under the terms of the Creative Commons Attribution 4.0 International License (http://creativecommons.org/licenses/by/4.0/), which permits unrestricted use, distribution, and reproduction in any medium, provided you give appropriate credit to the original author(s) and the source, provide a link to the Creative Commons license, and indicate if changes were made. The Creative Commons Public Domain Dedication waiver (http://creativecommons.org/publicdomain/zero/1.0/) applies to the data made available in this article, unless otherwise stated. 


\section{Background}

There is an increasing number of displaced persons in the world with approximately 68.5 million people having been forced out of their homes; 25.4 million of these individuals are refugees [1]. Refugees are more likely to have experienced severe traumatic events in their home countries such as torture, rape, murder of family members, and have a higher incidence of post-traumatic stress disorder (PTSD) [2]. Most displaced persons and refugees are found in low and middle income settings, including sub-Saharan Africa which hosts more than $26 \%$ of the world's refugee population [1].

Uganda is host to over 1.5 million refugees coming from Democratic Republic of Congo (44\%), South Sudan (38\%), Somalia (7\%), Rwanda (8\%) and Burundi (3\%) [1]. Since 1998 the Democratic Republic of Congo has undergone successive war and armed conflicts that resulted in over 5.4 million deaths [3]. South Sudan has been devastated by civil war since December 2013 which resulted in about 400,000 deaths, 190,000 the direct result of fighting [4]. Likewise, a deadly civil war has ravaged Somalia since 1991 [5]. Burundi underwent a civil war from 1993 to 2005 which was followed by periods of political disturbances [6]. In Rwanda, in 1994, a genocide resulted in over 800,000 deaths in only three months [7]. Refugees tend to remain in Uganda for decades due to the extended nature of regional conflicts and their political aftermaths [8].

The refugees in Uganda are hosted in 11 main settlement camps (Achol-Pii Settlement, Bidi Bidi Settlement, Impevi Settlement, Kampala Settlement, Kiryandongo Settlement, Kyaka II Settlement, Kyangwali Settlement, Nakivale Settlement, Pagirinya Settlement, Rhino Settlement, Rwamwanaja Settlement). A considerable part of the refugees in Uganda (17\%) are located in Nakivale camp in Insigiro District, south-western Uganda. Nakivale Refugee Settlement camp is characterized by a protracted situation in which refugee stay is not limited in time, assistance aims to enable local long term installation and self-reliance and refugees in Nakivale are allowed to move out the camp for business, work, recreation or any other reason [9]. Previous studies in Ugandan refugee camps have focused on PTSD and have shown a higher prevalence compared to other camps in the world. In northern Uganda, PTSD was found in $46 \%$ of Sudanese refugees and $18 \%$ of Ugandan nationals [10]. Among Somali community refugees, it was reported that $32 \%$ of adults suffer from PTSD [11]. Two previous studies in Nakivale refugee settlement, one among the Congolese reported PTSD prevalence of $61.7 \%$ [12]; and the second among the Rwandan and Somali refugees reported respectively 32 and $48.1 \%$ [13]. Daily life stressors in refugee camp settings may worsen PTSD and other psychiatric problems. Many studies have found a strong association between current stressors and mental health outcomes among traumatized populations $[2,14,15]$. This growing body of evidence has motivated the recommendation of psychosocial support and prioritizing addressing basic needs in addition to trauma-focused interventions [16]. Despite current efforts to address psychosocial needs of displaced persons, it is crucial to systematically analyse the vague concept of 'current stressors' in order to determine the main needs which are more likely to be associated with mental health outcomes among refugees. A clear understanding of driving factors can inform the efficient organization of scarce resources to help reduce suffering.

Prior studies done in Uganda evaluated specific nationalities, and were limited to PTSD and depression [12, 13, 17]. While prevalence of PTSD and Major Depressive Disorder (MDD) is shown to be high in refugee camp settings, knowledge of other psychiatric disorders and co-morbidities such as anxiety disorders and substance use disorder, can help guide treatment and intervention. Understanding the experience of various nationalities and, in turn, various cultures within the same context can be useful as well. Furthermore, understanding the association between basic psychosocial needs and psychiatric illness can help in the planning and provision of relevant psychosocial management and medical strategies for vulnerable populations.

\section{Methods}

\section{Study design and setting}

We conducted a cross sectional community survey in Nakivale Refugee Settlement in south-western Uganda. The camp hosts about 97,271 refugees of which $54 \%$ are female. There are nine nationalities of refugees in Nakivale camp including 44,270 (45.51\%) Congolese, 26, 243 (26.91\%) Burundians, 16,136 (16.59\%) Somalis, 8933 (9.18\%) Rwandans, 794 (0.81\%) Ethiopians, 745 (0.77) Eritreans, $101(0.10 \%)$ South-Sudanese, 21 (0.2\%) Sudanese, 23 (0.02\%) Kenyans and $5(0.01 \%)$ Senegalese [1]. This setting was selected for its accessibility, large number of refugees and their representativeness regarding different nationalities.

\section{Participant recruitment}

We used the Kish Leslie formula [18] to determine the sample size, considering a PTSD prevalence of $61.7 \%$ reported in a previous study among Congolese refugees in Nakivale camp [12]. The minimum sample size was 363 respondents. In order to account for incompleteness or loss of information, we increased the number by $7 \%$ to have a total of 387 respondents. Quota and stratified sampling were used to ensure representation of various nationalities in the camp. The strata consisted of 9 different nationalities present in the camp. The number of participants in each stratum was calculated proportionally from the representativeness of each nationality in the overall number of refugees in Nakivale. Hence, the sample constituted 176 Congolese, 104 
Burundians, 64 Somalis, 36 Rwandans, 3 Ethiopian, 3 Eritreans, 1 Sudanese. In each stratum, the participants were randomly sampled from the registration list of the camp using random number generator in Excel. Eligible participants were adults refugees (recognized by the Ugandan Office of the Prime Minister under the 1951 Convention relating to the status of refugees), 18 years old and above, and living in the camp for at least 6 months. We excluded refugees who had serious mental disorders which were identified as any psychological disturbance disabling the participant to complete the interview or give sound responses (1 person), had extreme physical disabilities (6 persons) and those with communication deficiencies like speech and hearing impairments which would make it impossible for them to comprehend the questions being asked ( 2 persons). We recruited participants between April and May 2017. Six research assistants fluent in English and at least two other languages used by refugees (Swahili, Kirundi, Kinyarwanda, Arabic and Omoro) collected the data. The research assistants were selected among community health workers working within the refugee camp health care system and familiar with the environment. The principal investigator trained the research assistants over 5 days emphasizing the theoretical and practical aspects of the data collection tool, informed consent and participant confidentiality.

\section{Ethical approval}

Ethical approval was obtained from Mbarara University of Science and Technology. Research Ethics committee and the Uganda National Council for Science and Technology. The permission to carry out the study in the camp was obtained from the Office of the Prime Minister. Written informed consent was obtained from the participants and privacy and confidentiality of the participants was ensured. Participants determined to have mental illness were referred to the psychiatric department of Mbarara Regional Referral Hospital for appropriate care.

\section{Measures}

Socio-demographic data were collected using a locallygenerated socio-demographic questionnaire and information collected included age, sex, marital status, nationality and education level.

Psychiatric disorders were assessed using the MINI International Neuropsychiatric Interview 7 (MINI). The MINI is a short, structured diagnostic interview compatible with the Diagnostic and Statistical Manual of Mental Disorders 5. It was designed for clinical practice, research in psychiatric primary care settings and epidemiological surveys $[19,20]$. The MINI was chosen based on the validity and reliability demonstrated in different populations in Uganda, Brazil, Japan and Europe [21-23].

Perceived needs were assessed using the Humanitarian Emerging Settings Perceived Needs Scale (HESPER) scale developed by the World Health Organization and King's College London. It explores a wide range of perceived social, psychological and physical needs of people affected by large-scale humanitarian emergencies such as war, conflict or major natural disasters. Pilot-testing of HESPER was done by Semrau et al. [24] in the United Kingdom with Congolese refugees, in Jordan and in Gaza to assess the scale's feasibility, intelligibility and cultural applicability (2012). The assessment of psychometric properties (i.e. reliability and validity) was done by the same team in Jordan, Haiti and Nepal [24]. HESPER was used in Nepal [25] and in South Sudan [26] to assess psychosocial needs among refugees. HESPER scale contains 26 items on physical, social and psychological needs perceived by respondents as 'serious problems'. Participants indicated if they perceived each item (Table 3) as a 'serious problem' or not. A percentage of respondents who rated the item as a 'serious problem' was calculated to understand the magnitude of the need.

The socio-demographic questionnaire, the MINI and the HESPER constituted the data collection tool used in the field.

\section{Translation}

The entire questionnaire was translated into five local languages spoken by all nine nationalities of refugees in the camp (Swahili, Kirundi, Kinyarwanda, Arabic and Omoro) using blind back translation and subsequent corrections by different translators. Translation was done by research assistants under the supervision of the main investigator and a different group of translators back translated into English. The original and the backtranslated questionnaires were compared to assess how accurately each item was translated. Items found to be less accurately translated were discussed further to arrive at translations best mirroring the original item.

\section{Data analysis}

The data were analysed using STATA version 13 for both descriptive and inferential analysis. Descriptive statistics were done using univariate analysis to calculate the outcomes (mental disorders) and predictor variables (demographic factors and perceived needs). All qualitative variables were described in the form of frequencies and percentages. We used univariate analysis for sociodemographic factors, perceived needs and psychiatric disorders. We used bivariate analysis to determine the association between socio-demographic risk factors and sex. We used bivariate and multiple logistic regression to determine the association between PTSD and sociodemographic factors, other psychiatric disorders as well as perceived needs using the individual odds ratio (95\% confidence intervals). The associations were deemed significant with a $P$-value less than 0.05 . Variables were 
included in multiple regression when they were associated with PTSD at a P-value less than 0.05. Then, we performed a Bonferroni correction [27] to control for the familywise error.

\section{Results}

\section{Sociodemographic characteristics of participants}

We enrolled 387 participants aged 18 years and above. Table 1 shows the demographic characteristics of the participants. Overall, a majority of the participants were females $(n=219,56.59 \%)$, married ( $n=188,48.58 \%)$, Congolese $(n=176,45.48 \%)$ and had attained secondary education $(n=207,53.48 \%)$. The mean age was 33.01 (SD 12.2) and the mean duration in the camp was 4.29 years (SD of 3.43).

\section{Psychiatric disorders among study participants}

The most prevalent psychiatric disorder was generalized anxiety disorder (73\%), followed by PTSD (67\%), major depressive disorder (58\%), and substance use disorders (30\%). Among participants with PTSD, 70\% also met criteria for major depressive disorder, $82 \%$ had generalized anxiety disorder and 30\% had substance use disorder (Table 2).

\section{Perceived needs of the participants}

Overall most participants reported having a 'serious problem' with almost all the psychosocial perceived needs. The most frequently cited perceived needs were issues related to 'separation from family members' and 'caring for people in the community who are alone' and 'distress'. The least reported needs were 'law and justice in the community' and 'moving between places.' There was strong agreement between men and women in their perception of the most serious psychosocial needs. However women more often reported 'having a serious problem with safety' $(P$-value $=0.04)$ and 'education for the children' $(P$-value $=0.04)($ Table 3$)$.

\section{Factors associated with PTSD}

The main psychiatric outcomes (major depressive disorder, generalized anxiety disorder, and substance and alcohol use disorders) and socio-demographic factors were run in bivariate analysis with PTSD. A multivariate logistic regression was then conducted including the factors that were significantly associated with PTSD in bivariate analysis. Multivariate logistic regression showed that the odds of having PTSD was 5.13 times higher among participants having substance use disorders [OR $=5.13(2.32-11.34)$; $P$ value $<0.0001$ ], 3.27 times higher for those having generalized anxiety disorder $[\mathrm{OR}=43.27(1.85-5.76)$; P-value <

Table 1 Demographic characteristics of the study participants $(n=387)$

\begin{tabular}{|c|c|c|c|}
\hline Variables & $N(\%)$ or Mean (SD) & Male $(n, \%)$ & Female $(n, \%)$ \\
\hline$\overline{\text { Age }}$ & $33(12)$ & $31(12)$ & $35(12)$ \\
\hline Number of years in Nakivale & $4.29(3.43)$ & $4.09(3.42)$ & $4.44(3.44)$ \\
\hline \multicolumn{4}{|l|}{ Marital Status } \\
\hline Married & $188(49)$ & $76(45)$ & $112(51)$ \\
\hline Single & $158(41)$ & $88(52)$ & $70(32)$ \\
\hline Divorced & $8(2)$ & $0(0)$ & $8(4)$ \\
\hline Separated & $3(1)$ & $1(1)$ & $2(1)$ \\
\hline Widowed & $30(8)$ & $3(2)$ & $27(12)$ \\
\hline \multicolumn{4}{|l|}{ Nationality } \\
\hline Burundian & $104(27)$ & $44(26)$ & $60(27)$ \\
\hline Congolese & $176(45)$ & $92(55)$ & $84(38)$ \\
\hline Eritrean & $3(1)$ & $1(1)$ & $2(1)$ \\
\hline Ethiopian & $3(1)$ & $1(1)$ & $2(1)$ \\
\hline Rwandese & $36(9)$ & $14(8)$ & $22(10)$ \\
\hline Somali & $64(16)$ & $15(9)$ & $49(22)$ \\
\hline Sudanese & $1(0)$ & $1(1)$ & $0(0)$ \\
\hline \multicolumn{4}{|l|}{ Level of Education } \\
\hline Under Primary & $113(29)$ & $30(18)$ & $83(38)$ \\
\hline Primary & $76(20)$ & $29(17)$ & $47(21)$ \\
\hline Secondary & $174(45)$ & $90(54)$ & $84(38)$ \\
\hline University & $24(6)$ & $19(11)$ & $5(2$ \\
\hline
\end{tabular}


Table 2 Distribution of Psychiatric disorders among participants

\begin{tabular}{|c|c|c|c|c|}
\hline Variables & $\operatorname{PTSD}(N, \%)$ & Major depressive Disorder $(N, \%)$ & Generalized Anxiety Disorder ( $N, \%)$ & Substance Used disorder $(N, \%)$ \\
\hline \multicolumn{5}{|l|}{ Sex } \\
\hline Male & $116(69)$ & $103(61)$ & $121(72)$ & $69(32)$ \\
\hline Female & $144(66)$ & $123(56)$ & $160(73)$ & $49(29)$ \\
\hline \multicolumn{5}{|l|}{ Age } \\
\hline$\leq 20$ & $28(70)$ & $23(58)$ & $26(65)$ & $12(30)$ \\
\hline $21-30$ & $106(63)$ & $87(51)$ & $124(73)$ & $36(21)$ \\
\hline $31-40$ & $64(70)$ & $65(71)$ & $69(75)$ & $37(40)$ \\
\hline $41-50$ & $34(67)$ & $30(59)$ & $39(76)$ & $21(41)$ \\
\hline$>50$ & $28(80)$ & $21(60)$ & $23(66)$ & $12(34)$ \\
\hline \multicolumn{5}{|l|}{$\begin{array}{l}\text { Number of years in } \\
\text { Nakivale }\end{array}$} \\
\hline$\leq 5$ years & $192(68)$ & $172(61)$ & $208(73)$ & $79(28)$ \\
\hline$>5$ years & $68(66)$ & $54(52)$ & $73(71)$ & $39(38)$ \\
\hline \multicolumn{5}{|l|}{ Marital Status } \\
\hline Married & $131(70)$ & $112(60)$ & $139(74)$ & $62(33)$ \\
\hline Single & $100(63)$ & $90(57)$ & $111(70)$ & $48(30)$ \\
\hline Divorced & $6(75)$ & $3(37)$ & $5(62)$ & $2(25)$ \\
\hline Separated & $3(100)$ & $3(100)$ & $3(100)$ & $2(67)$ \\
\hline Widowed & $20(67)$ & $18(60)$ & $23(68)$ & $4(13)$ \\
\hline \multicolumn{5}{|l|}{ Nationality } \\
\hline Burundian & $78(75)$ & $64(62)$ & $75(72)$ & $17(16)$ \\
\hline Congolese & $115(65)$ & $91(52)$ & $131(74)$ & $45(26)$ \\
\hline Somali & $39(61)$ & $45(70)$ & $43(67)$ & $35(55)$ \\
\hline Other nationalities & $28(65)$ & $26(62)$ & $32(71)$ & $21(45)$ \\
\hline \multicolumn{5}{|l|}{ Level of Education } \\
\hline under Primary & $79(70)$ & $69(61)$ & $84(74)$ & $42(37)$ \\
\hline Primary & $49(64)$ & $46(61)$ & $56(74)$ & $21(28)$ \\
\hline Secondary & $116(67)$ & $96(55)$ & $123(71)$ & $43(25)$ \\
\hline University & $16(67)$ & $15(62)$ & $18(75)$ & $12(50)$ \\
\hline Total & $260(67)$ & $226(58)$ & $281(73)$ & $118(30)$ \\
\hline
\end{tabular}

0.0001] and 4.04 times higher for those having major depressive disorder [OR = 4.04 (2.24-7.30); P-value < 0.0001]. We observed however that being Somali $[\mathrm{OR}=0.16(0.06-$ $0.41)$; P-value $<0.01$ ] was less associated with PTSD. After application of Bonferroni correction PTSD, substance use disorders, generalized anxiety disorder, major depressive disorder and being Somali remained significantly associated to PTSD. Results are summarized in Table 4.

\section{Psychosocial perceived needs associated with PTSD}

A bivariate and multivariate analysis was used to assess the association between perceived needs and PTSD. In bivariate analysis, many psychosocial perceived needs were associated with PTSD. Most notably, the odds of perceiving 'distress' as a 'serious problem' is 18 times higher in people with PTSD [OR $=18.10(6.19-52.93)$; $P$ - value $<0.0001]$. The other perceived needs associated with PTSD were issues associated with healthcare [OR = $2.46(1.46-4.15) ; P$-value $<0.0001]$, the way aid is provided $[\mathrm{OR}=2.31(1.38-3.88) ; P$-value $<0.0001]$, or not having a place to live in [OR $=2.29(1.43-3.67)$; P-value $<0.0001]$. After controlling for confounding factors in a multivariate logistic regression, only the perception of 'stress' as a 'serious problem' $[\mathrm{OR}=6.52(1.87-9.76)$; $\mathrm{P}$ value $=0.003]$, 'safety and protection for women in the community' $[\mathrm{OR}=2.35 \quad(1.21-4.56) ; \quad \mathrm{P}$-value $=0.011]$, 'care for family' [OR $=2.00(1.10-5.17)$; P-value $=0.035]$ and 'place to live in' $[\mathrm{OR}=1.83(1.02-3.22)$; $\mathrm{P}$-value $=$ 0.041] were significantly associated with PTSD at the 0.05 P-value. After the Bonferroni correction, only the perception of 'distress' remained significantly associated with PTSD (Table 5). 
Table 3 HESPER Perceived Needs of Participants by gender

\begin{tabular}{|c|c|c|c|c|}
\hline Item & $N(\%)$ & Male (\%) & Female (\%) & $P$-Value \\
\hline \multicolumn{5}{|l|}{ Do you have a serious problem with ... } \\
\hline Separation from family members & $369(95)$ & $163(44)$ & $205(56)$ & 0.12 \\
\hline Care for people who are on their own & $362(94)$ & $159(44)$ & $203(56)$ & 0.44 \\
\hline Addressing psychological Distress & $355(92)$ & $157(44)$ & $198(56)$ & 0.28 \\
\hline Mental illness in the community & $344(89)$ & $149(43)$ & $195(57)$ & 0.91 \\
\hline Safety & $334(86)$ & $152(46)$ & $182(54)$ & 0.04 \\
\hline Being displaced from home & $333(86)$ & $140(42)$ & $193(58)$ & 0.18 \\
\hline Alcohol or drug use in the community & $330(85)$ & $148(45)$ & $182(55)$ & 0.17 \\
\hline Education for the children & $330(85)$ & $136(41)$ & $194(59)$ & 0.04 \\
\hline Food & $327(84)$ & $142(43)$ & $185(57)$ & 0.99 \\
\hline Income or livelihood & $322(83)$ & $142(44)$ & $180(56)$ & 0.54 \\
\hline Respect & $318(82)$ & $140(44)$ & $178(56)$ & 0.60 \\
\hline Care for family members & $316(82)$ & $134(42)$ & $182(58)$ & 0.40 \\
\hline Healthcare & $315(81)$ & $139(44)$ & $176(56)$ & 0.55 \\
\hline The way aid is provided & $313(81)$ & $140(45)$ & $173(55)$ & 0.28 \\
\hline Too much free time & $307(80)$ & $131(43)$ & $176(57)$ & 0.64 \\
\hline Safety or protection from violence for women & $302(78)$ & $132(44)$ & $170(56)$ & 0.65 \\
\hline Physical health & $296(76)$ & $136(46)$ & $160(54)$ & 0.07 \\
\hline Place to live in & $287(74)$ & $127(44)$ & $160(56)$ & 0.57 \\
\hline Toilets & $273(71)$ & $127(47)$ & $146(53)$ & 0.12 \\
\hline Clothes, shoes, bedding or blankets & $272(70)$ & $114(42)$ & $158(58)$ & 0.36 \\
\hline Keeping clean & $266(69)$ & $118(44)$ & $148(56)$ & 0.58 \\
\hline Drinking water & $261(67)$ & $108(41)$ & $153(59)$ & 0.25 \\
\hline Support from others & $248(64)$ & $105(42)$ & $143(58)$ & 0.57 \\
\hline Information & $196(51)$ & $90(46)$ & $106(54)$ & 0.31 \\
\hline Law and justice in the community & $111(29)$ & $48(43)$ & $63(57)$ & 0.97 \\
\hline Moving between places & $70(18)$ & $31(18)$ & $39(18)$ & 0.87 \\
\hline
\end{tabular}

\section{Discussion}

This study is the first study to assess the prevalence of concurrent major psychiatric illness in Nakivale camp. Furthermore, it is one of few studies systematically assessing perceived needs among refugees in a subSaharan African refugee camp. Overall, our results show a high prevalence of PTSD, major depressive disorder, generalized anxiety disorder and substance use among refugees in Nakivale camp. PTSD is highly comorbid with other psychiatric disorders and is associated with perceived psychosocial needs.

A higher prevalence of mental health concerns were identified compared to similar studies among refugees in both pre and post-resettlement settings [28-33]. Two previous studies conducted in Nakivale found relatively high prevalence of PTSD, 61.7\% among Congolese refugees and $48.1 \%$ among Somali refugees [17, 34]. However, those figures are lower than the prevalence found in this study $(67 \%)$. It is possible that the differences are due to differences in methodology. First, we used a different tool from previous studies conducted in Nakivale camp. The two previous studies used Post traumatic score diagnostic scale [35] which assesses PTSD symptoms by providing a continuous severity score; the authors set an arbitrary cutoff to distinguish between refugees with and without PTSD. On this point, this scale contrasts with the MINI used in our study which clearly gives results in terms of presence or absence of PTSD according to the core and secondary symptoms described by the DSM V. Secondly, unlike the two previous studies, we included participants from the nine nationalities present in the camp and the tools have been translated in five different languages. It is also possible that the hardship of life has worsened with the changing number of new refugees and limited aid response over time [36]. Finally, it is also possible that these differences in rates of PTSD were due to higher levels of traumatization in different home countries at different times. 
Table 4 Factors associated with PTSD

\begin{tabular}{|c|c|c|c|c|}
\hline Factors associated with PTSD & Unadj OR (95\% Cl) & P-value & Adj OR $(95 \% \mathrm{Cl})$ & P-value \\
\hline Substance use disorders & $6.95(3.31-14.59)$ & $<0.0001$ & $5.13(2.32-11.33)$ & $<0.001$ \\
\hline Generalized anxiety disorder & $4.05(2.35-6.98)$ & $<0.0001$ & $3.27(1.85-5.76)$ & $<0.001$ \\
\hline Major Depressive Disorder & $4.11(2.45-6.91)$ & $<0.0001$ & $4.04(2.24-7.30)$ & $<0.001$ \\
\hline \multicolumn{5}{|l|}{ Marital status } \\
\hline Married & $0.33(0.05-2.09)$ & 0.24 & - & - \\
\hline Single & $0.26(0.04-1.64)$ & 0.15 & - & - \\
\hline Separated & Reference & & Reference & \\
\hline Widowed & $0.25(0.03-1.86)$ & 0.18 & - & - \\
\hline \multicolumn{5}{|l|}{ Nationality } \\
\hline Burundian & Reference & & & \\
\hline Congolese & $0.55(0.28-1.05)$ & 0.07 & - & - \\
\hline Somali & $0.16(0.06-0.40)$ & $<0.0001$ & $0.16(0.06-0.41)$ & $<0.01$ \\
\hline Other nationalities & $0.43(0.24-1.23)$ & 0.43 & - & - \\
\hline \multicolumn{5}{|l|}{ Number of years in the camp } \\
\hline Below 5 years & Reference & & & \\
\hline Above 5 years & $1.33(0.74-2.40)$ & 0.34 & - & - \\
\hline \multicolumn{5}{|l|}{ Level of Education } \\
\hline under Primary degree & Reference & & Reference & \\
\hline Primary degree & $0.74(0.36-1.55)$ & 0.43 & - & - \\
\hline Secondary degree & $1.07(0.55-2.11)$ & 0.84 & - & - \\
\hline University & $0.58(0.20-1.96)$ & 0.38 & - & - \\
\hline
\end{tabular}

Bold indicates correlation is significant at alpha level corrected by sequential Bonferroni method [27]

In our study, there was a significant association between PTSD and substance use disorder, major depressive disorder and anxiety disorder. Our findings are in agreement with those of previous research which reported a high rate of psychiatric comorbidities in patients with PTSD in refugees living both in Western and African countries. In Norway, it was found that $80 \%$ of refugees with PTSD had additional diagnoses such as anxiety disorder, substance use disorders and psychotic disorders [37]. Among Cambodian refugees resettled in the USA, PTSD was highly associated with generalized anxiety disorder [38], and PTSD and major depression were highly comorbid ( $42 \%$ of refugees having both PTSD and MDD) [39]. Among Somali refugees in Nairobi, PTSD was reported to be strongly associated with use of khat [40]. PTSD, depression and anxiety have common overlapping symptoms that can explain to some extent this high association [41, 42]. Flory JD and Yehuda $R$. have argued that depression is possibly a trauma-related phenotype, a subtype of PTSD [43].

Our results also show a strong association between perceived needs and psychiatric outcomes. The perceived needs associated with PTSD in bivariate analysis were perception of distress, issues associated with care for family members, healthcare, the way aid is provided, place to live in, income or livelihood, safety or protection from violence for women in the community, education for the children, physical health, food, too much free time, toilets and support from others. In multivariate analysis perception of stress as a serious problem, issues with respect to safety and protection for women in the community, care for family and place to live in remained associated with PTSD. After Bonferroni correction, the perception of stress remained significantly associated to PTSD. Existing literature consistently points to the association between daily stressors and the psychiatric outcomes both in refugees resettled in Western countries and those living in African countries [38, 44-48]. In Africa, among Darfur refugees in Chad, lack of access to basic resources and the perception of lack of safety predicted more mental health outcomes than previous exposure to trauma [44]. Among internally displaced persons in Uganda, PTSD was associated with lack of water or food and experiencing illness without medical care [47]. Moreover in a large systematic review concerning low and middle income countries, socioeconomic factors, such as being unemployed, poor living conditions, and being female were associated with poor psychological health in conflict-affected populations [46]. Among Somali refugees of Melkadida camp being deprived of shelter was associated with depression [30]. 
Table 5 HESPER Perceived needs associated with PTSD among refugees in Nakivale camp

\begin{tabular}{|c|c|c|c|c|}
\hline Perceived Need & Unadj OR (95\% Cl) & P-Value & Adj OR $(95 \% \mathrm{Cl})$ & $P$-Value \\
\hline Distress & $18.10(6.19-52.93)$ & $<0.0001$ & $6.52(1.87-9.76)$ & 0.003 \\
\hline Care for family members & $3.66(2.15-6.22)$ & $<0.0001$ & $2.00(1.02-3.22)$ & 0.035 \\
\hline Healthcare & $2.46(1.46-4.15)$ & $<0.0001$ & $1.21(0.45-3.57)$ & 0.731 \\
\hline The way aid is provided & $2.31(1.38-3.88)$ & $<0.0001$ & $1.19(0.64-3.45)$ & 0.75 \\
\hline Place to live in & $2.29(1.43-3.67)$ & $<0.0001$ & $1.83(1.02-3.22)$ & 0.042 \\
\hline Income or livelihood & $2.14(1.25-3.69)$ & 0.01 & $1.72(1.02-3.48)$ & 0.048 \\
\hline Safety for women in the community & $2.13(1.30-3.52)$ & $<0.0001$ & $2.35(1.21-4.56)$ & 0.011 \\
\hline Education for the children & $2.07(1.17-3.66)$ & 0.01 & $1.41(0.64-3.15)$ & 0.39 \\
\hline Physical health & $1.88(1.16-3.06)$ & 0.01 & $1.12(0.82-2.21)$ & 0.63 \\
\hline Food & $1.86(1.06-3.25)$ & 0.03 & $0.86(0.52-2.23)$ & 0.74 \\
\hline Too much free time & $1.85(1.12-3.08)$ & 0.01 & $1.15(0.67-2.22)$ & 0.723 \\
\hline Toilets & $1.60(1.02-2.53)$ & 0.04 & $1.14(0.86-2.61)$ & 0.34 \\
\hline Support from others & $1.60(1.03-2.48)$ & 0.03 & $1.18(0.91-2.45)$ & 0.54 \\
\hline Safety & $1.55(0.85-2.80)$ & 0.15 & & \\
\hline Separation from family members & $1.52(0.60-3.88)$ & 0.38 & - & - \\
\hline Mental illness in the community & $1.39(0.72-2.66)$ & 0.32 & - & - \\
\hline Being displaced from home & $1.36(0.75-2.47)$ & 0.31 & - & - \\
\hline Clothes, shoes, bedding or blankets & $1.34(0.85-2.11)$ & 0.21 & - & - \\
\hline Respect & $1.23(0.76-2.23)$ & 0.34 & - & - \\
\hline Care for people in the community who are on their own & $1.16(0.50-2.71)$ & 0.72 & - & - \\
\hline Alcohol or drug use in the community & $1.13(0.62-2.03)$ & 0.69 & - & - \\
\hline Drinking water & $0.98(0.62-1.54)$ & 0.94 & - & - \\
\hline Information & $0.97(0.63-1.48)$ & 0.88 & - & - \\
\hline Law and justice in the community & $0.86(0.54-1.37)$ & 0.54 & - & - \\
\hline Keeping clean & $0.86(0.54-1.37)$ & 0.52 & - & - \\
\hline Moving between places & $0.47(0.28-0.80)$ & 0.01 & $0.49(0.29-1.04)$ & 0.01 \\
\hline
\end{tabular}

Bold indicates correlation is significant at alpha level corrected by sequential Bonferroni method [27]

Among refugees resettled in Western countries, similar observations were made. In Iraqi refugees in Jordan, factors such as inadequate housing, unemployment and change in family structures may play a big role in the occurrence of depression, anxiety disorder and substance use disorders among refugees [25]. Among traumatized Cambodian refugees living in USA, worry about life concerns like lacking of financial resources, children not attending school and health concerns worsened PTSD [38].

In this current study, Somalis presented fewer symptoms of PTSD compared to other populations. The reason for this difference is unclear and should motivate additional studies of proportioned groups of participants. It is possible these differences are due to the fact that the tools were translated in different languages. A difference in livehoods between different nationalities has also been reported in the camp with Somalis being more successful entrepreneurs and having more social cohesion [49].

This body of evidence suggests that unmet perceived needs may play a detrimental role in the psychopathology of PTSD. Furthermore, a study by Bruhn et al. showed clearly how post-migration stressors are complicating treatment of trauma among refugees [50]. Therefore it is important to plan interventions that clearly identify the unmet basic needs associated with more mental outcomes, to address the basic needs, and to integrate them into humanitarian mental health policy.

Unlike some studies which identified being female as associated with poor mental health outcomes [46], our study did not find a significant difference between sex in terms of psychiatric disorders. This lack of difference may reinforce the argument that psychiatric disturbances are connected to the importance of perceived needs in the population. In our study the kind and salience of perceived needs showed a strong similarity between the two sexes, thus, it is possible that the similar prevalence of psychiatric disturbances is connected to these similar perceptions. It is also possible that that there was not a difference in exposure to traumatic events between women and men. A study of Somali and Ethiopian 
refugees living in the United States identified similarities between sexes with respect to trauma experienced [51].

Thus, high perceived unmet needs are associated with psychiatric outcomes. Complicating this, refugees with mental disturbances are often less able to work and to provide for their needs. Finally, displacement puts refugees in general in a vulnerable position, they are less able to find employment, and therefore cannot independently fulfill their basic needs. The provisions and care provided by aid agencies are not sufficient to fill the large gap of unmet needs.

\section{Limitations}

This study has some limitations. As a cross-sectional study it is not possible to confirm a cause-and-effect relationship between the independent variables and the psychiatric outcomes. In addition, the stratified sampling technique we used may lead to few participants in some minority subgroups. Our limited sample size and the number of variables tested may have impacted the results. Finally, although the tools used to assess psychiatric outcomes and psychosocial perceived needs have been used in Uganda and multiple other African countries, the tools have not been adapted and validated across different nationalities and languages in the camp and this could have contributed to higher prevalences detected.

\section{Conclusion}

This study highlights the high prevalence and cooccurrence of mental disorders among refugees in Nakivale camp and their association with perceived psychosocial needs. The findings suggest that the higher prevalence found in Nakivale camp may be related to the high level of unmet basic needs. Hence, the magnitude and complexity of psychiatric disturbances should mobilize psychosocial support. Furthermore, mental health programs should include a systematic screening and holistic management including clinical approaches and supplementation of basic needs. Interventions aiming at addressing the social needs of refugees are needed in addition to addressing their mental health. Interventions for these populations should therefore include the identification of the basic needs most associated with mental health outcomes and address those that are modifiable. Studies of the long-term impact of such holistic interventions, including longitudinal and, if possible, randomized studies are necessary to continue to build the evidence base for effective approaches to improving the mental health and well-being of refugee populations in Africa and elsewhere.

\section{Abbreviations}

HESPERS: The Humanitarian Emerging Settings Perceived Needs Scale; MINI: Mini International Neuropsychiatric Interview; OR: Odd Ratio; PTSD: Post-Traumatic Stress Disorder; SD: Standard Deviation; UNHCR: United Nation High Commission of Refugee

\section{Acknowledgements}

Thanks to Professor Samuel Marling, Dr. Robyn Fallen and Maria Birna for their comments on earlier drafts of this paper. Thanks to Dr. Mari Dumbaugh for reading our draft and for her helpful comments. Thanks to DAAD and fUNIKIN-BEBUC for having funded our Masters studies in psychiatry.

\section{Authors' contributions}

$\mathrm{AB}$ designed the study, carried out data collection, data analysis, and preparation of the firs tand revised drafts of the manuscript,. SS contributed to the study design, and contributed to the preparation and editing of the manuscript. CK contributed to the study design, carried out data collection and contributed to the preparation and editing of the manuscript. GR contributed to the design of the study and to the preparation and editing of the manuscript. SA contributed to the study design, carried out data collection and contributed to the preparation and editing of the manuscript. All authors have read and have approved the manuscript.

\section{Funding}

This study has been funded by the NGO Förderverein Uni Kinshasa e. V., fUNIKIN, Else-Kroener-Fresenius Stiftung, Holger-Poehlmann Foundation through the excellence scholarship program "Bourse d'Excellence Bringmann aux Universités Congolese,BEBUC".

\section{Availability of data and materials}

The datasets used and/or analysed during the current study are available from the corresponding author on reasonable request.

Ethics approval and consent to participate

We sought ethical approval from Mbarara University of Science and Technology Ethics committee and the Uganda National Council of Science and Technology. We obtained written informed consent from the participants.

\section{Consent for publication}

"Not applicable".

\section{Competing interests}

The authors declare that they have no competing interests.

\section{Author details}

${ }^{1}$ Department of Psychiatry, Hôpital Provincial Général de Référence de Bukavu, Université Catholique de Bukavu, Bukavu, DR, Congo. ²Department of Psychiatry, Mbarara University of Science and Technology, Mbarara, Uganda. ${ }^{3}$ Department of Psychiatry and Behavioural Sciences, George Washington University, Washington, DC, USA.

Received: 25 April 2019 Accepted: 3 February 2020

Published online: 07 February 2020

\section{References}

1. UNHCR. UNHCR populations statistics. UNHCR Rapport. 2018; popstats. unhcr.org.

2. Steel Z, Chey T, Silove D, Marnane C, Bryant RA, Van Ommeren M. Association of torture and other potentially traumatic events with mental health outcomes among populations exposed to mass conflict and displacement: a systematic review and meta-analysis. Jama. 2009;302(5):537-49.

3. Moszynski P. 5.4 million people have died in Democratic Republic of Congo since 1998 because of conflict, report says. Bmj. 2008;336(7638):235 Epub 2008/02/05.

4. Krause J. Stabilization and local conflicts: communal and civil war in South Sudan. Ethnopolitics. 2019;18(5):478-93.

5. Zeid AA, Cochran JJ. Understanding the crisis in Somalia. Significance. 2014; 11(1):4-9.

6. Vandeginste S. Power-sharing, conflict and transition in Burundi: twenty years of trial and error. Afr Spectr. 2009;44(3):63-86.

7. Hintjens HM. Explaining the 1994 genocide in Rwanda. J Mod Afr Stud. 1999;37(2):241-86

8. Hovil L. Self-settled refugees in Uganda: an alternative approach to displacement? J Refug Stud. 2007;20(4):599-620.

9. Ilcan S, Oliver M, Connoy L. Humanitarian assistance and the politics of selfreliance: Uganda's Nakivale refugee settlement; 2015. 
10. Karunakara UK, Neuner F, Schauer M, Singh K, Hill K, Elbert T, et al. Traumatic events and symptoms of post-traumatic stress disorder amongst Sudanese nationals, refugees and Ugandans in the West Nile. Afr Health Sci. 2004;4(2):83-93.

11. Peltzer K. Trauma and mental health problems of Sudanese refugees in Uganda. The Central African journal of medicine. 1999;45(5):110-4.

12. Ssenyonga J, Owens V, Olema DK. Posttraumatic growth, resilience, and posttraumatic stress disorder (PTSD) among refugees. Procedia Soc Behav Sci. 2013;82:144-8.

13. Onyut LP, Neuner, F. Ertl, V., Schauer, E., Odenwald, M., Elbertz, T. Mental Health among Somali and Rwandese refugees living in an African Refugee Settlement: an Epidemiological Study. Conflict and Health. 2009;doi:10.1186:1752-505-3-6.

14. Li SS, Liddell BJ, Nickerson A. The relationship between post-migration stress and psychological disorders in refugees and asylum seekers. Curr Psychiatry Rep. 2016;18(9):82.

15. Schweitzer R, Melville F, Steel Z, Lacherez P. Trauma, post-migration living difficulties, and social support as predictors of psychological adjustment in resettled Sudanese refugees. Aust N Z J Psychiatry. 2006;40(2):179-88.

16. WHO. UNHCFR. Operational guidance. Mental health \& psychosocial support programming for refugee operations. Geneva: United Nations High Commissioner for Refugees. 2013.

17. Senyaonga J, Owens V., Olema, D.K. Post-traumatic growth, resilience, and post-traumatic, stress disorder among refugees. Social and Behavioural Sciences 2013:82:144-148.

18. Kish WH, L. Survey sampling. John Wiley \& Sons, Inc., New York, London 1965, IX+ 643 S., 31 Abb., 56 tab., Preis 83 s. Biom Z. 1968;10(1):88-9.

19. van Vliet IM, de Beurs E. The MINI-International Neuropsychiatric Interview. A brief structured diagnostic psychiatric interview for DSM-IV en ICD-10 psychiatric disorders]. Tijdschrift voor psychiatrie. 2007:49(6):393-7. Epub 2007/07/07. Het Mini Internationaal Neuropsychiatrisch Interview (MINI). Een kort gestructureerd diagnostisch psychiatrisch interview voor DSM-IV- en ICD-10-stoornissen.

20. Sheehan DV, Lecrubier Y, Sheehan KH, Amorim P, Janavs J, Weiller E, et al. The MiniInternational Neuropsychiatric Interview (M.I.N.I): the development and validation of a structured diagnostic psychiatric interview for DSM-IV and ICD-10. The Journal of clinical psychiatry. 1998;59 Suppl 20:22-33;quiz 4-57. Epub 1999/01/09.

21. de Azevedo Marques JM, Zuardi AW. Validity and applicability of the Mini international neuropsychiatric interview administered by family medicine residents in primary health care in Brazil. Gen Hosp Psychiatry. 2008;30(4): 303-10 Epub 2008/07/01.

22. Otsubo T, Tanaka K, Koda R, Shinoda J, Sano N, Tanaka S, et al. Reliability and validity of Japanese version of the Mini-international neuropsychiatric interview. Psychiatry Clin Neurosci. 2005;59(5):517-26 Epub 2005/10/01.

23. Sheehan DV, Sheehan KH, Shytle RD, Janavs J, Bannon Y, Rogers JE, et al. Reliability and validity of the Mini international neuropsychiatric interview for children and adolescents (MINI-KID). The Journal of clinical psychiatry. 2010;71(3):313-26 Epub 2010/03/25.

24. Semrau M, van Ommeren M, Blagescu M, Griekspoor A, Howard LM, Jordans $\mathrm{M}$, et al. The development and psychometric properties of the humanitarian emergency settings perceived needs (HESPER) scale. Am J Public Health. 2012:102(10):e55-63 Epub 2012/08/18.

25. Jordans MJ, Semrau M, Thornicroft G, van Ommeren M. Role of current perceived needs in explaining the association between past trauma exposure and distress in humanitarian settings in Jordan and Nepal. The British journal of psychiatry : the journal of mental science. 2012;201(4):27681 Epub 2012/07/31

26. Ayazi T, Swartz L, Eide AH, Lien L, Hauff E. Perceived current needs, psychological distress and functional impairment in a war-affected setting: a cross-sectional study in South Sudan. BMJ Open. 2015;5(8):e007534 Epub 2015/08/21.

27. Holm S. A simple sequentially rejective multiple test procedure. Scand J Stat. 1979:65-70

28. Mills E, Singh S, Roach B, Chong S. Prevalence of mental disorders and torture among Bhutanese refugees in Nepal: a systemic review and its policy implications. Medicine, conflict, and survival. 2008;24(1):5-15 Epub 2008/05/07.

29. Sabin M, Lopes Cardozo B, Nackerud L, Kaiser R, Varese L. Factors associated with poor mental health among Guatemalan refugees living in Mexico 20 years after civil conflict. Jama. 2003;290(5):635-42 Epub 2003/08/07.

30. Feyera F, Mihretie G, Bedaso A, Gedle D, Kumera G. Prevalence of depression and associated factors among Somali refugee at Melkadida camp. Southeast Ethiopia: a cross-sectional study BMC Psychiatry. 2015;15: 171 Epub 2015/07/25.

31. Slewa-Younan S, Uribe Guajardo MG, Heriseanu A, Hasan T. A systematic review of post-traumatic stress disorder and depression amongst Iraqi refugees located in Western countries. Journal of immigrant and minority health / Center for Minority Public Health. 2015;17(4):1231-9 Epub 2014/06/06.

32. Fenta H, Hyman I, Noh S. Determinants of depression among Ethiopian immigrants and refugees in Toronto. J Nerv Ment Dis. 2004;192(5):363-72 Epub 2004/05/06

33. Kane JC, Ventevogel P, Spiegel P, Bass JK, van Ommeren M, Tol WA. Mental, neurological, and substance use problems among refugees in primary health care: analysis of the health information system in 90 refugee camps. BMC Med. 2014;12:228 Epub 2014/11/26.

34. Onyut LP, Neuner F, Ertl V, Schauer E, Odenwald M, Elbert T. Trauma, poverty and mental health among Somali and Rwandese refugees living in an African refugee settlement-an epidemiological study. Confl Heal. 2009;3(1):6.

35. Foa E. Posttraumatic stress diagnostic scale manual. Minneapolis, MN: National Computer Systems; 1995.

36. Ilcan S, Oliver M, Connoy L. Humanitarian assistance, refugee management, and self-reliance schemes: Nakivale refugee settlement 1. Transnational Social Policy: Routledge; 2017. p. 152-77.

37. Teodorescu DS, Heir T, Hauff E, Wentzel-Larsen T, Lien L. Mental health problems and post-migration stress among multi-traumatized refugees attending outpatient clinics upon resettlement to Norway. Scand J Psychol. 2012;53(4):316-32 Epub 2012/05/23.

38. Hinton DE, Nickerson A, Bryant RA. Worry, worry attacks, and PTSD among Cambodian refugees: a path analysis investigation. Soc Sci Med. 2011;72(11): 1817-25 Epub 2011/06/15.

39. Marshall GN, Schell TL, Elliott MN, Berthold SM, Chun CA. Mental health of Cambodian refugees 2 decades after resettlement in the United States. Jama. 2005;294(5):571-9 Epub 2005/08/04.

40. Odenwald M, Hinkel H, Schauer E, Schauer M, Elbert T, Neuner F, et al. Use of khat and posttraumatic stress disorder as risk factors for psychotic symptoms: a study of Somali combatants. Soc Sci Med. 2009:69(7):1040-8 Epub 2009/08/12.

41. Brady KT, Killeen TK, Brewerton T, Lucerini S. Comorbidity of psychiatric disorders and posttraumatic stress disorder. The Journal of clinical psychiatry. 2000;61(Suppl 7):22-32 Epub 2000/05/05.

42. Price M, Legrand AC, Brier ZM, Hebert-Dufresne L. The symptoms at the center: examining the comorbidity of posttraumatic stress disorder, generalized anxiety disorder, and depression with network analysis. J Psychiatr Res. 2019;109:52-8.

43. Flory JD, Yehuda R. Comorbidity between post-traumatic stress disorder and major depressive disorder: alternative explanations and treatment considerations. Dialogues Clin Neurosci. 2015;17(2):141.

44. Rasmussen A, Nguyen L, Wilkinson J, Vundla S, Raghavan S, Miller KE, et al. Rates and impact of trauma and current stressors among Darfuri refugees in eastern Chad. The American journal of orthopsychiatry. 2010;80(2):227-36 Epub 2010/06/18

45. Batniji R, Van Ommeren M, Saraceno B. Mental and social health in disasters: relating qualitative social science research and the sphere standard. Soc Sci Med. 2006;62(8):1853-64 Epub 2005/10/06.

46. Roberts B, Browne J. A systematic review of factors influencing the psychological health of conflict-affected populations in low- and middleincome countries. Glob Public Health. 2011;6(8):814-29 Epub 2010/09/23.

47. Roberts B, Ocaka KF, Browne J, Oyok T, Sondorp E. Factors associated with post-traumatic stress disorder and depression amongst internally displaced persons in northern Uganda. BMC Psychiatry. 2008;8:38 Epub 2008/05/21.

48. Gerritsen AA, Bramsen I, Deville W, van Willigen LH, Hovens JE, van der Ploeg HM. Physical and mental health of afghan, Iranian and Somali asylum seekers and refugees living in the Netherlands. Soc Psychiatry Psychiatr Epidemiol. 2006;41(1):18-26 Epub 2005/12/13.

49. Omata N, Kaplan JD. Refugee livelihoods in Kampala, Nakivale and Kyangwali refugee settlements: patterns of engagement with the private sector: refugee studies Centre, Oxford Department of International Development; 2013.

50. Bruhn M, Rees S, Mohsin M, Silove D, Carlsson J. The range and impact of postmigration stressors during treatment of trauma-affected refugees. J Nerv Ment Dis. 2018;206(1):61-8.

51. Jaranson JM, Butcher J, Halcon L, Johnson DR, Robertson C, Savik K, et al, Somali and Oromo refugees: correlates of torture and trauma history. Am J Public Health. 2004:94(4):591-8 Epub 2004/04/01.

\section{Publisher's Note}

Springer Nature remains neutral with regard to jurisdictional claims in published maps and institutional affiliations. 